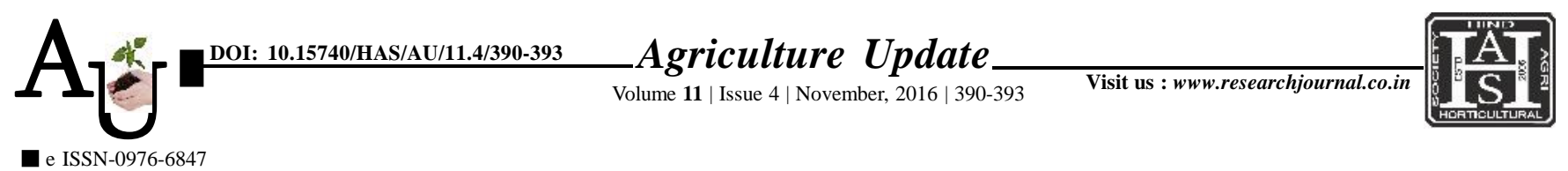

\title{
Research Article: Extent of adoption of integrated pest management practices by the brinjal growers and its correlates
}

\author{
口.K. BANSOD, R.T. KATOLE AND G.B. MORE
}

Article Chronicle:

Received :

12.08.2016;

Revised :

25.09.2016;

Accepted :

11.10.2016

KEY WoRDS :

Adoption,

Brinjal,

Correlation
SUMMARY : The present research study was conducted on 120 brinjal growers from 12 villages comprising 6 villages each from Saoner and Katol tahasils of Nagpur district of Vidarbha region of Maharashtra state to ascertain the adoption level of farmers about integrated pest management practices by the brinjal growers. The results revealed that more than half of the respondents $(64.14 \%)$ were included under medium category of adoption level of integrated pest management practices. As regards to the finding of relational analysis revealed that, among the selected variables education, land holding, area under brinjal, experiences in cultivation of brinjal crop, annual income, sources of information, social participation, risk preference, economic motivation and innovativeness were positively and significantly correlated with adoption of integrated pest management practices of brinjal. Whereas, variable like age did not show any significant relation with adoption by brinjal growers.

How to cite this article : Bansod, S.K., Katole, R.T. and More, G.B. (2016). Extent of adoption of integrated pest management practices by the brinjal growers and its correlates. Agric. Update, 11(4): 390-393; DOI : 10.15740/HAS/AU/11.4/390-393. 